\title{
The characteristics of LTP induced in hippocampal slices are dependent on slice-recovery conditions
}

\author{
Brigitte Capron, ${ }^{1,2}$ Christian Sindic, ${ }^{2}$ Emile Godaux, ${ }^{1,3}$ and Laurence Ris ${ }^{1}$ \\ ${ }^{1}$ Department of Neurosciences, University of Mons-Hainaut, 7000 Mons, Belgium; ${ }^{2}$ Department of Neurology, Université \\ Catholique de Louvain, 1000 Brussels, Belgium
}

\begin{abstract}
In area CAl of hippocampal slices which are allowed to recover from slicing "in interface" and where recordings are carried out in interface, a single 1-sec train of $100-\mathrm{Hz}$ stimulation triggers a short-lasting long-term potentiation (S-LTP), which lasts 1-2 h, whereas multiple 1-sec trains induce a long-lasting LTP (L-LTP), which lasts several hours. Moreover, the threshold and the features of these LTP depend on the history of the neurons, a phenomenon known as metaplasticity. Here, where all recordings were performed in interface, we found that allowing the slices to recover "in submersion" had dramatic metaplastic effects. In these conditions, a single 1-sec train at $100 \mathrm{~Hz}$ induced an L-LTP which lasted at least $4 \mathrm{~h}$ and was dependent on protein synthesis. Interestingly, this type of metaplasticity was observed when the concentration of $\mathrm{Mg}^{++}$used was $1.0 \mathrm{mM}$ but not when it was $1.3 \mathrm{mM}$. The LTP induced by four 1-sec trains at $100 \mathrm{~Hz}$ was similar whatever the incubation method. However, the signaling cascades recruited to achieve that pattern were different. In the interface-interface paradigm (recovery and recording both in interface) the four-train induced LTP recruited the PKA signaling pathway but not that of the p42/44MAPK. On the contrary, in the submersion-interface paradigm the four-train induced LTP recruited the p42/44MAPK signaling pathway but not that of the PKA. To our knowledge this is the first example of metaplasticity involving the recruitment of signaling cascades in LTP.
\end{abstract}

Long-term potentiation (LTP) of synaptic transmission is believed to play an important role in encoding memories in neuronal networks (Bliss and Collingridge 1993; Martin et al. 2000). This phenomenon was first discovered on an in vivo preparation (Bliss and Lomo 1973) but the foremost improvements in deciphering its mechanisms were obtained on the in vitro brain slice preparation (Collingridge et al. 1983; Lynch et al. 1983; Frey et al. 1993; Nguyen et al. 1994; Abel et al. 1997; Giese et al. 1998; Kandel 2001).

There are two different techniques to maintain brain slices alive for hours (Dingledine et al. 1980). In the interface-slice preparation, slices are partially submerged in artificial cerebrospinal fluid (ACSF) with the top surface of the slice exposed to a humidified atmosphere of $95 \% \mathrm{O}_{2}$ and $5 \% \mathrm{CO}_{2}$. In this case the slice gets oxygen that is diffused through the very thin film of liquid covering the slice. In the submerged-slice preparation, slices are completely submerged in ACSF. In this case, the oxygen supply to the slice is provided by the oxygen dissolved in the ACSF. Researchers use one technique or another depending upon the technical constraints of their experiments. For instance, experiments where imaging measurements are performed using a confocal microscope require the use of the submerged-slice preparation. However, these two different techniques can have different effects on cell physiology. For instance, it was recently found that phosphorylation of alpha calcium/calmodulindependent kinase II ( $\alpha$ CaMKII) at T286, a phosphorylation playing a key role in LTP (Giese et al. 1998), was transiently increased in slices maintained in submersion but was persistently decreased in slices maintained in interface chambers (Ho et al. 2004).

Moreover, there are two different steps in each experiment. After slicing, slices must be left undisturbed (recovery period) for $1.5 \mathrm{~h}$ before starting the recordings (recording period). Recovery

\footnotetext{
${ }^{3}$ Corresponding author.

E-mail emile.godaux@umh.ac.be; fax 3265373573.

Article published online before print. Article and publication date are at http:// www.learnmem.org/cgi/doi/10.1101/lm.135406.
}

and recording are not necessarily carried out in the same type of chamber (submersion or interface). For instance, in some studies slices recover in interface and are subsequently tested in a submersion chamber whereas in other experiments recovery and recording are made in submersion. Synaptic plasticity is sensitive not only to the induction stimulus but also to what occurred earlier in the synapse. The fact that synaptic plasticity is dependent on the history of the synapse is known as "metaplasticity" (Abraham and Bear 1996; Abraham and Tate 1997). For instance, inhibition of LTP can be elicited by priming stimulation below threshold for LTP or LTD induction (Christie and Abraham 1992; Huang et al. 1992). Application of the mGluR agonist 1S, 3Raminocyclopentanedicarboxylic acid (ACPD) leads to a facilitation of LTP induction and persistence, as elicited later by a tetanus normally just above threshold for LTP induction (Cohen and Abraham 1996). It is even possible that a stimulation, which alone has no effect on synaptic plasticity, inhibits the late phase of LTP, a phenomenon called "silent metaplasticity" by Woo and Nguyen (2002). Thus, it could be that the type of chamber used for having the slices recovered (submersion or interface) would influence the characteristics of the LTP subsequently induced in interface conditions. Here we found this to be the case.

\section{Results}

Facilitation of induction of long-lasting LTP by recovery in submersion

When the experiments were performed in ACSF containing $\mathrm{Mg}^{++}$ at a concentration of $1 \mathrm{mM}$, the way in which the slices were allowed to recover (submersion or interface) had a dramatic influence on the duration of the LTP induced by a single train of high-frequency stimulation $(100 \mathrm{~Hz}, 1 \mathrm{sec})$ (Fig. $1 \mathrm{~A}, \mathrm{~B})$.

When both recovery and recording occurred in interface, one train elicited an initial potentiation of the slope of the field excitatory postsynaptic potential (fEPSP) reaching $177 \pm 9 \%$ (mean \pm SEM). Four hours later, it was reduced to $111 \pm 7 \%$ of 
A
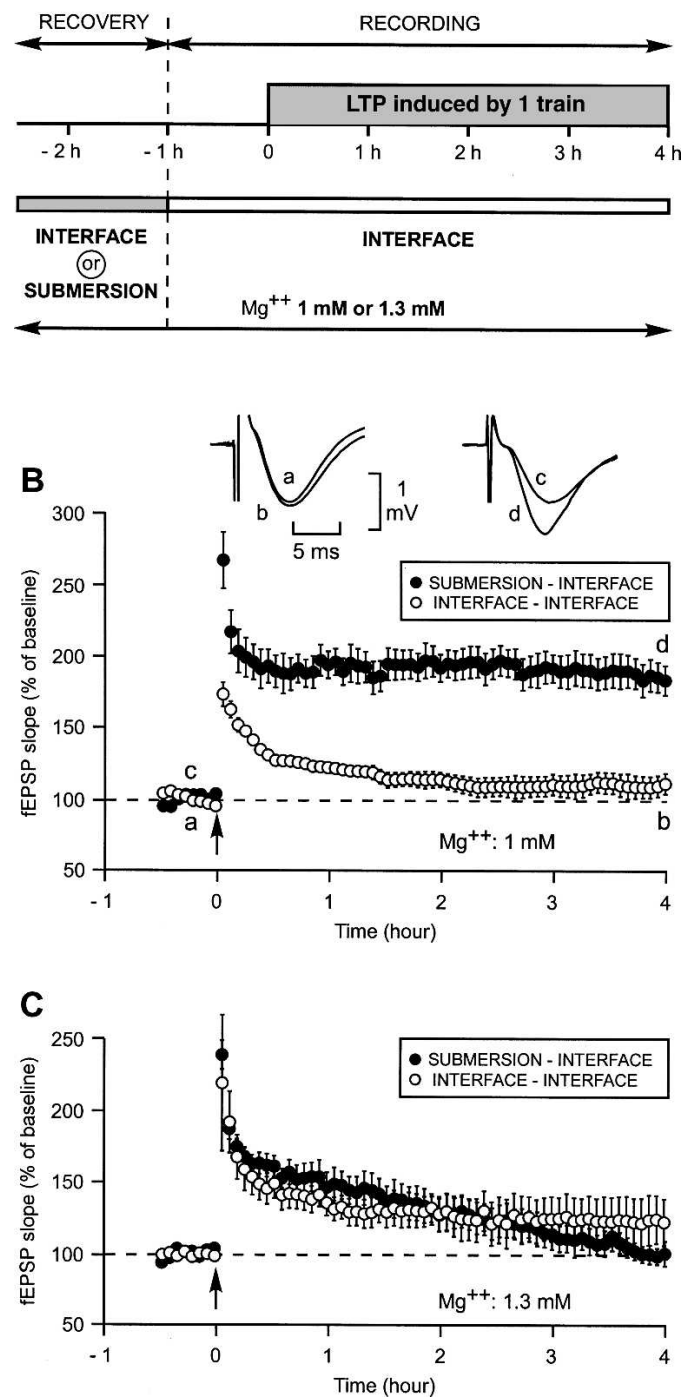

Figure 1. Induction by a single train of high-frequency stimulation (100 Hz, $1 \mathrm{sec}$ ) (HSF) of a long-lasting LTP (L-LTP) instead of a shortlasting LTP (S-LTP) by allowing the slices to recover in submersion instead of in interface. (A) Experimental paradigm. Slices could recover either in submersion or in interface. All recordings were carried out in interface. $\mathrm{Mg}^{++}$concentration was either $1.3 \mathrm{mM}$ or $1 \mathrm{mM}$ throughout the same experiment. (B) Comparison of LTP triggered by a single train in slices bathed in ACSF with an $\mathrm{Mg}^{++}$concentration of $1 \mathrm{mM}$ when slices recovered either in submersion $(\mathbf{0})$ or in interface $(\bigcirc)$. When recovery occurred in submersion an L-LTP was triggered $(\bullet)$ instead of an S-LTP, which was observed when recovery occurred in interface $(\bigcirc)$. Inset: sample fEPSP traces from one experiment are shown; they were recorded just before ( $a$ and $c$ ) and $4 \mathrm{~h}$ after ( $b$ and $d$ ) the induction stimulation. Traces $a$ and $b$ were recorded in an experiment where the recovery of the slice occurred in interface; traces $c$ and $d$ were recorded in an experiment where recovery occurred in submersion. (C) The priming effect of submersion was not observed when experiments were carried out at a $\mathrm{Mg}^{++}$concentration of $1.3 \mathrm{mM}$.

baseline, a level not significantly different from pre-induction level $(P=0.09)$. The duration of the LTP, measured by the time at which the increase of the fEPSP slope ceased to be different from the baseline, was $1 \mathrm{~h} 30 \mathrm{~min}$ (Fig. 1B). By contrast, when slices first recovered in submersion and were subsequently studied in the interface condition, a single train induced a strong and longlasting LTP. The initial potentiation was of $268 \pm 20 \%$. Over the next 10 subsequent min it diminished to $199 \pm 14 \%$ and then remained nearly stable, reaching $189 \pm 19 \% 4 \mathrm{~h}$ after LTP induction, a value significantly higher than that measured in the interface-interface paradigm $(111 \pm 7 \%, P<0.05)$.

This effect was not related to a change in the general excitability of the neurons. The amplitudes of the baseline fEPSPs were similar in both conditions $(1.3 \pm 0.1 \mathrm{mV}$ after recovery in submersion and $1.4 \pm 0.1 \mathrm{mV}$ after incubation in interface, $P=0.6$ ), as were the input-output curves. The width of the fEPSPs were also similar across the two conditions $(9.1 \pm 0.4 \mathrm{msec}$ in the submersion-interface paradigm vs. $9.2 \pm 0.6 \mathrm{msec}$ in the other paradigm, $P=0.9$ ).

Surprisingly, the difference induced by the incubation method was not observed when the experiments were carried out in a medium where the concentration of $\mathrm{Mg}^{++}$was $1.3 \mathrm{mM}$ (Fig. $1 \mathrm{C})$. In such a medium, the LTP measured $4 \mathrm{~h}$ after induction was not different from baseline, whether recovery occurred in interface $(120 \pm 14 \%, P=0.47)$ or in submersion $(100 \pm 9 \%$, $P=0.18)$. This shows that a small modification in the concentration of $\mathrm{Mg}^{++}$can have a great influence on certain biological responses.

\section{Properties of the facilitated L-LTP}

We then studied the properties of the L-LTP elicited, surprisingly, by a single train in the experimental conditions used here (submersion-interface $\left./ \mathrm{Mg}^{++}: 1 \mathrm{mM}\right)$. When slices were bathed in a solution containing cycloheximide (CHX), an inhibitor of protein synthesis, from $30 \mathrm{~min}$ before to $45 \mathrm{~min}$ after LTP induction, the late phase of potentiation was hindered (Fig. 2A). Under the influence of cycloheximide $(80 \mu \mathrm{M})$, the LTP measured $4 \mathrm{~h}$ after induction was reduced to $135 \pm 16 \%$ (mean \pm SEM), a level different from that measured in control slices $(P<0.05)$ and not different from the basal level $(P=0.11)$.

The long-lasting LTP induced by a single train in our experimental conditions was thus dependent on protein synthesis. However, it was not dependent on the signaling pathway of PKA (Fig. 2B) but on that of ERK (or p42/44MAPK) (Fig. 2C). When slices were submitted to KT5720 $(1 \mu \mathrm{M})$, an inhibitor of PKA, the LTP triggered by one train was $162 \pm 21 \% 4 \mathrm{~h}$ after induction, a level not different from that measured in control slices $(P=0.35)$ and different from baseline $(P<0.05)$. By contrast, when slices bathed in a medium containing U0126 $(20 \mu \mathrm{M})$, an inhibitor of MEK, which is the kinase that activates ERK specifically, the LTP measured $4 \mathrm{~h}$ after induction $(133 \pm 16 \%)$ was significantly lower than the control LTP $(P<0.05)$ and not significantly different from the baseline $(P=0.11)$.

\section{Signaling pathways involved in the facilitated L-LTP}

In a subsequent series of experiments, we explored the potential role of different signaling pathways in the dramatically increased duration of the LTP induced by one single train after allowing the slices to recover in submersion. With such a goal in mind, slices were submitted to different pharmacological agents during the recovery period (Fig. 3).

It was found that the positive metaplasticity induced by the recovery in submersion was impaired when p38MAPK was inhibited by SB203580 $(10 \mu \mathrm{M})$, by MCPG $(500 \mu \mathrm{M})$, an inhibitor of metabotropic glutamate receptors, and when Cs $(1 \mathrm{mM})$ was applied. Four hours after its induction, LTP was as low as $115 \pm 13 \%, 113 \pm 13 \%$ and $115 \pm 12 \%$ when the slices were submitted to the influence of SB203580; MCPG; and Cs, respectively. Each of these three levels were lower than that of control LTP $(P<0.05)$.

By contrast, no de novo protein synthesis was involved in the metaplasticity phenomenon described above. Protein syn-

\section{Learning \& Memory}

www.learnmem.org 

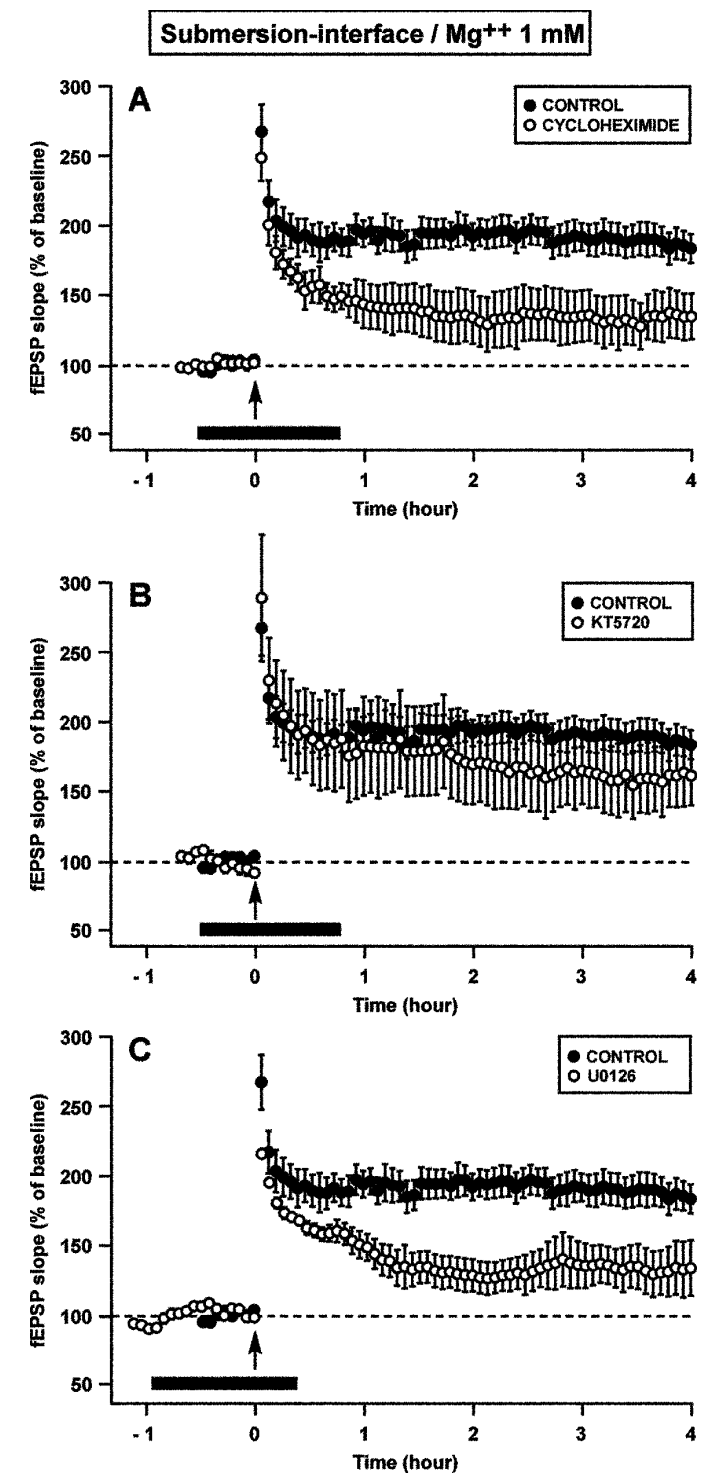

Figure 2. The L-LTP induced by a single train of HFS in a slice that had recovered in submersion is dependent on protein synthesis and on ERK (p42/44MAPK) but not on PKA. (A) Time course of fEPSP slope 30 min before and $4 \mathrm{~h}$ after a $1-\mathrm{sec}$ train in the control situation $(0)$ and in presence of cycloheximide $(\mathrm{CHX})$, an inhibitor of protein synthesis $(\bigcirc)$. The potentiation was significantly reduced $4 \mathrm{~h}$ after the train when cycloheximide was present around the time of induction (black bar). (B) Time course of fEPSP slope in presence of KT5720, an inhibitor of PKA $(\bigcirc)$. The potentiation was not different from the control $(\bullet)$. (C) Time course of fEPSP slope in presence of U0126, an inhibitor of MEK (O). The potentiation $4 \mathrm{~h}$ after the train was significantly lower than the control potentiation (-). All the experiments presented in this figure were carried out at a $\mathrm{Mg}^{++}$concentration of $1 \mathrm{mM}$.

thesis was inhibited by cycloheximide $(40 \mu \mathrm{M})$ during the recovery period. In these conditions, LTP was not different from control values $4 \mathrm{~h}$ after induction $(158 \pm 19 \%, P=0.24)$. Similarly, bathing the slices during recovery in a medium containing either APV (50 microM), an inhibitor of the NMDA receptor, or U0126 $(20 \mu \mathrm{M})$, an inhibitor of MEK, did not suppress the type of metaplasticity shown in Figure 1B. Four hours after induction, the mean LTP was lower than that of the control $(149 \pm 25 \%$ for APV and $132 \pm 26 \%$ for U0126) but these differences were not statistically significant $(P=0.22, P=0.09)$.
Influence of recovery in submersion on the recruitment of signaling pathways in LTP

It is known that distinct signaling cascades can be recruited in function of the different induction paradigms. Thus, we decided to investigate whether a change in the recovery procedure (interface vs. submersion) could modify the recruitment of the various signaling cascades in a paradigm using a stronger induction stimulus, such as four trains separated from each other by an interval of 5 min (Fig. 4).

Submersion-interface $/ \mathrm{Mg}^{++} 1 \mathrm{mM}$
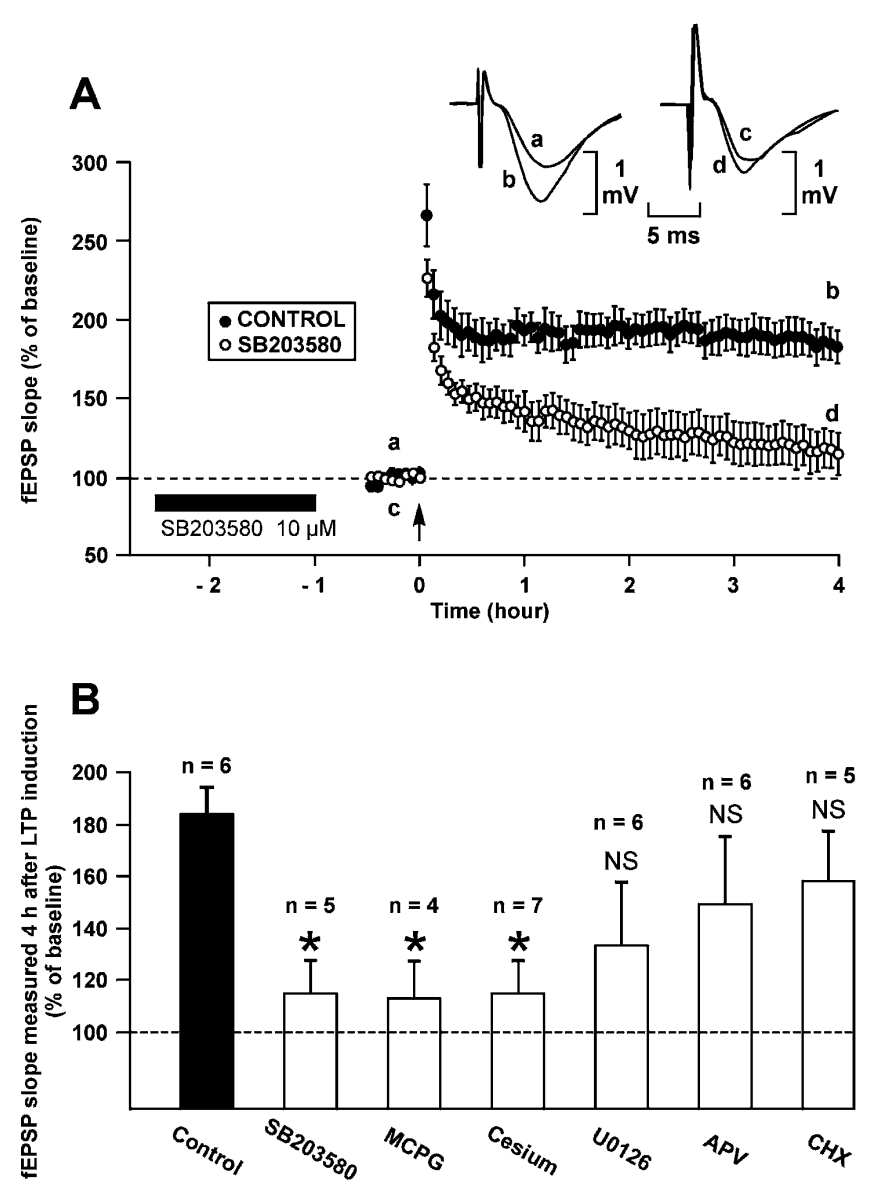

Figure 3. The metaplastic phenomenon induced by the in-submersion recovery of the slices (L-LTP induced by one train) is blocked by an inhibitor of p38MAPK (SB203580), an inhibitor of metabotropic glutamate receptors (MCPG) and cesium but not by inhibitors of MEK (U0126), of NMDA receptor (APV) and of protein synthesis (CHX). (A) Time course of fEPSP slope $30 \mathrm{~min}$ before and $4 \mathrm{~h}$ after the train of HFS in the control situation (-) and when SB203580 was applied during the recovery period in submersion. The potentiation of the fEPSP slope was significantly reduced under the influence of SB203580. Inset: examples of fEPSP recorded in one experiment just before $(a, c)$ and $4 \mathrm{~h}$ after $(b, d)$ induction in the control situation (left) and when SB203580 was applied (right). Traces $a$ and $b$ were recorded in control situation; traces $c$ and $\mathrm{d}$ were recorded after the slice had recovered in submersion in presence of SB203580. (B) Percentage of potentiation of the fEPSP slope $4 \mathrm{~h}$ after induction in the control situation (black column) and after application of different drugs during the recovery period occurring in submersion (white columns). The number of experiments $(n)$ is indicated on the top of each column. The level of potentiation measured $4 \mathrm{~h}$ after induction was significantly lower than in the control situation when slices were submitted to the action of SB203580, MCPG or cesium. An asterisk points to a statistically significant decrease. NS = not statistically different. All the experiments referred to in this figure were carried out at a $\mathrm{Mg}^{++}$concentration of $1 \mathrm{mM}$. 

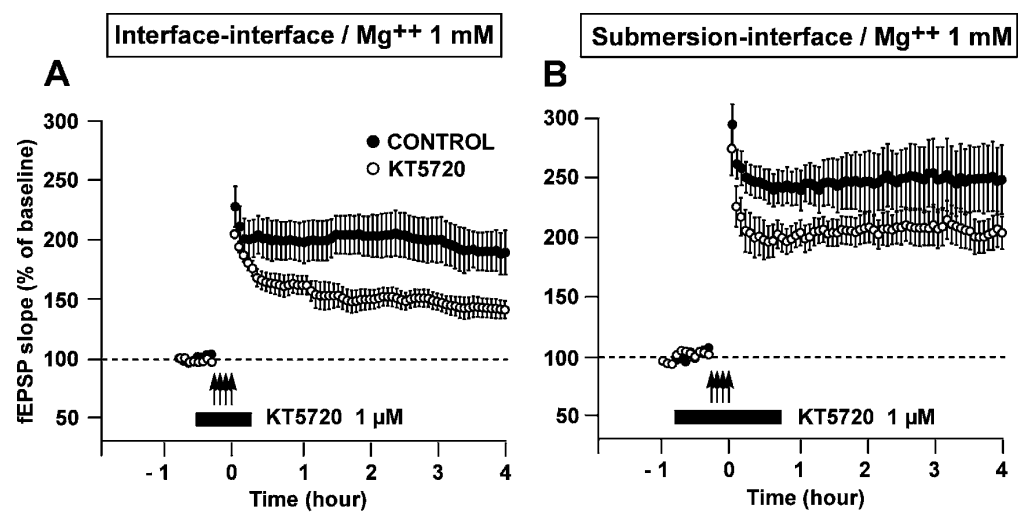

trains, the slope of the fEPSP was as low as $107 \pm 3 \%(n=5)$ which was not different from baseline $(P=0.25)$. By contrast, in the submersion-interface paradigm, the LTP was only partially NMDAdependent. In the presence of APV, the slope of the fEPSP was still as high as $149 \pm 8 \% 4 \mathrm{~h}$ after induction, which was a level lower than that reached in the absence of APV $(P<0.05)$ but higher than that of baseline $(P<0.05)$ (Fig. 5B).

The recruitment of different signaling pathways was also found to be influenced by the type of recovery (submersion vs. interface) when LTP was chemically induced by a 15-min perfusion of forskolin (FSK, an activator of adenylate cyclase, the enzyme that produces cAMP) and 3-isobutyl-1-methylxanthine (IBMX, an inhibitor of the phosphodiesterase involved in the destruction of cAMP) (Fig. 6).

For the same reason as explained before, all the experiments carried out in this section were done in ACSF containing $\mathrm{Mg}^{++} 1 \mathrm{mM}$.

The PKA signaling pathway was found to be necessary in the interfaceinterface but not in the submersioninterface paradigm, whereas the p42/ 44MAPK signaling pathway was necessary in both circumstances. In the interface-interface paradigm, the LTP measured $4 \mathrm{~h}$ after chemical induction, which was $155 \pm 15 \%$ in the control situation, was reduced to $107 \pm 8 \%$ $(P<0.05)$ under the influence of KT5720 and to $94 \pm 10 \%(P<0.05)$ under the

Figure 4. The recruitment of particular kinase cascades in the L-LTP induced by four trains of HFS $(100 \mathrm{~Hz}, 1 \mathrm{sec}, 5 \mathrm{~min}$ apart) depends on the type of recovery of the slices (in submersion versus in interface). (A-D) Time course of the fEPSP slope 30 min before and $4 \mathrm{~h}$ after four trains of HFS in the control situation ( $\bullet$ and when a drug was applied $(O)$. $(A, B)$ The PKA cascade, which is blockec was involved in L-LTP if recovery occurred in interface $A$ but not if it occurrec $B$. $(C, D)$ The p42/44MAPK cascade, which is blocked by U0126, was involved in L-LTP if recovery occurred in submersion $D$ but not if it took place in interface $C$. All the experiments gathered in this figure were performed at a $\mathrm{Mg}^{++}$concentration of $1 \mathrm{mM}$.

Because lowering the concentration of $\mathrm{Mg}^{++}$to $1 \mathrm{mM}$ was proven to be essential for the metaplasticity phenomenon described here, all the experiments in this section were performed using this concentration of $\mathrm{Mg}^{++}$.

When recovery occurred in interface, the L-LTP induced by four trains was dependent on the PKA signaling pathway and not on the p42/44MAPK pathway. On the contrary, when recovery took place in submersion, the L-LTP was sustained thanks to the p42/44MAPK pathway and was independent of the PKA pathway (Fig. 4).

Indeed, application of KT5720 $(1 \mu \mathrm{M})$ before, during and after induction caused a significant decrease in the LTP measured $4 \mathrm{~h}$ later in the interface-interface paradigm (141 $\pm 7 \%$ vs. $189 \pm 19 \%, P<0.05)$ but not in the submersion-interface paradigm $(204 \pm 14 \%$ vs. $249 \pm 29 \%, P=0.29)$. By contrast, submitting the slices to U0126 around the time of induction resulted in a significant decrease of LTP measured $4 \mathrm{~h}$ after induction in the submersion-interface paradigm (121 $\pm 9 \%$ vs. $249 \pm 29 \%$ in controls, $P<0.05)$ but there was no significant change in the interface-interface paradigm $(165 \pm 10 \%$ vs. $189 \pm 19 \%$ in controls, $P=0.27$ ).

As different cascades were involved in the two conditions, it was interesting to find out if the triggering $\mathrm{Ca}^{++}$influx operated through the same channels. We found this not to be the case. In the interface-interface paradigm, the LTP induced by four trains was strictly NMDA-dependent. Application of APV $(100 \mu \mathrm{M}) 30$ min before, during and $30 \mathrm{~min}$ after the trains completely suppressed the LTP (Fig. 5A). Four hours after the application of the action of U0126. In the submersion-interface paradigm, the LTP measured $4 \mathrm{~h}$ after induction was $204 \pm 19 \%$. It was not affected by KT5720 $(218 \pm 52 \%, P=0.73)$ but was significantly reduced when submitted to U0126 (118 $\pm 10 \%, P<0.05)$.

\section{Discussion}

Synaptic plasticity is sensitive not only to the "state" imposed by extra factors at the moment of LTP induction (Gelinas and Nguyen 2005), but also to the state created by certain factors prior to the induction (Abraham and Bear 1996; Abraham and Tate 1997). Here, we found that prior incubation in either submersion or interface conditions affected the nature of LTP subsequently induced in interface.

1. When the recovery of the slice occurred in submersion, a single train of $100-\mathrm{Hz}$ stimulation triggered an L-LTP instead of producing an S-LTP.

2. The L-LTP induced either by four electrical trains or application of FSK-IBMX recruited different signaling cascades in function of the type of recovery.

\section{Increased persistence of LTP}

The increase in persistence of LTP induced by prior incubation in submersion was not blocked by APV but it was by MCPG. Thus, contrary to a classic metaplastic effect (i.e., stimulation of a synapse at frequencies ranging from 5 to $30 \mathrm{~Hz}$ causes a dramatic reduction in subsequently evoked LTP), which is mediated by 

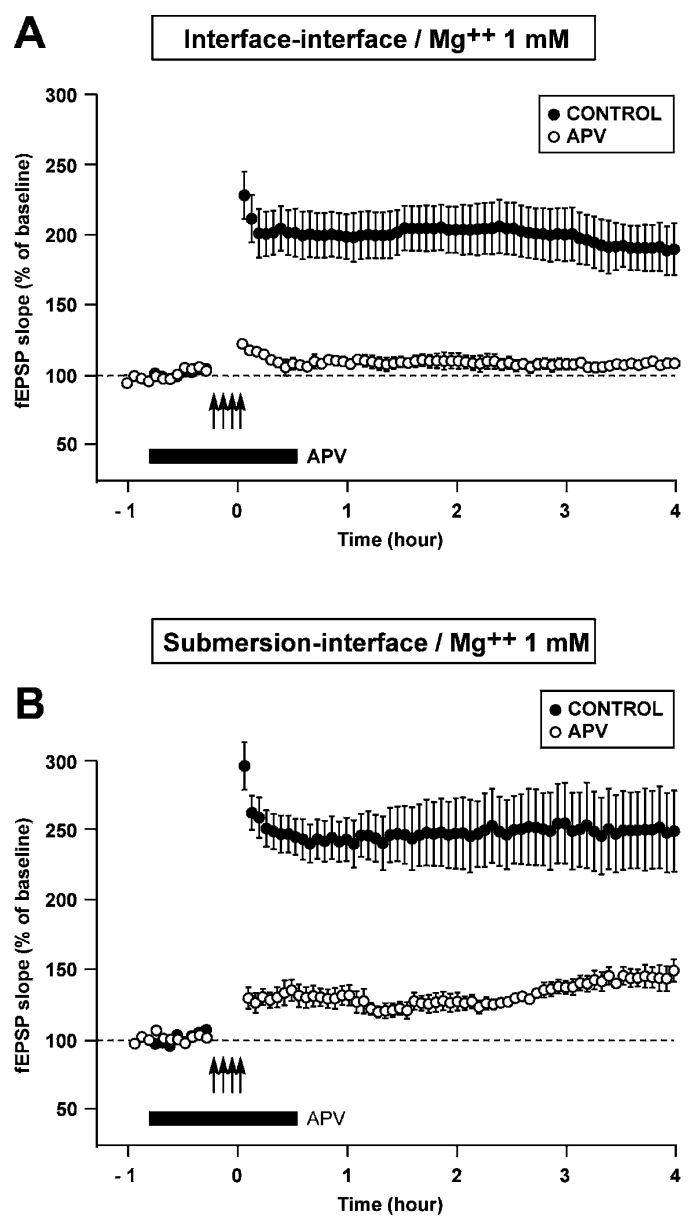

Figure 5. LTP induced by four trains of HFS was strictly NMDAdependent when recovery of the slices took place in interface but only partially NMDA-dependent when recovery occurred in submersion. $(A, B)$ Time course of the fEPSP slope $30 \mathrm{~min}$ before and $4 \mathrm{~h}$ after the four trains in the control situation $(\bullet)$ and when APV $(100 \mu \mathrm{M})$ was applied. In $A$, recovery occurred in interface. In $B$, it took place in submersion.

NMDA receptors (Huang et al. 1992; O'Dell and Kandel 1994; Zhang et al. 2005), ours involved an MCPG-sensitive receptor.

The known role of metabotropic glutamate (mGlu) receptors in LTP is complex. MCPG, an mGlu receptor antagonist, blocks LTP induction (Bashir et al. 1993). However, this inhibitory effect of MCPG can be suppressed by a 1-sec train stimulation applied hours earlier (Bortolotto et al. 1994). In this type of metaplasticity, the molecular switch involved is also set by the activation of an mGlu receptor since it is antagonized by MCPG. However, since the potent broad spectrum (mGlu1-8) mGlu receptor antagonist LY341495 blocks the setting of the molecular switch but not the induction of LTP per se, the receptors involved in these two effects must be different (Fitzjohn et al. 1998). MCPG has been found to block the setting of the molecular switch by activating the mGlu5 receptor whereas it prevents LTP induction by turning on a not yet identified mGlu receptor (Bortolotto et al. 2005). Moreover, LTP persistence can be increased by previous activation of group I mGlu receptors by the selective agonist DHPG (Cohen et al. 1998; Raymond et al. 2000). Here, we found that the persistence of the 1-sec train triggered LTP induced by the recovery of the slices in submersion was suppressed by MCPG. The precise receptor involved remains to be identified. It could be one of the known mGlu receptors expressed in the CA1 region and blocked by MCPG, which are mGlu1 and mGlu5 receptors (Shigemoto et al. 1997; Mannaioni et al. 2001) or the not yet identified MCPG-sensitive mGlu receptor.

When applied during the recovery period, cesium prevented the metaplasticity induced by the incubation conditions. Cesium is known to block several types of potassium channels: delayed rectifiers $(\mathrm{Kv}), \mathrm{K}_{\mathrm{A}}$ channels, big and small $\mathrm{Ca}^{++}$-activated $\mathrm{K}^{+}$channels (BK and SK), inward rectifier $\mathrm{K}^{+}$channels (Kir) (Hille 1992). Each of these $\mathrm{K}^{+}$channels tends to dampen neuronal excitability. Moreover, cesium also blocks Ih channels (Hille 1992). Like Kir channels, Ih channels open at negative potentials. Unlike Kir, however, they are as permeable to $\mathrm{Na}^{+}$as to $\mathrm{K}^{+}$ions. Ih channels also influence neuronal excitability but not in the same way as $\mathrm{K}^{+}$ channels. Because they let through an inward current when open, the effect of Ih channels is to initiate slow depolarization if the membrane potential has become very negative. Facing the multiple blocking patterns cesium can take, it is difficult to specify its way of acting on our metaplasticity effect. However, it cannot operate by inducing change in neuronal excitability still persistent at the time of LTP induction. Indeed, at that time, the amplitudes of the baseline fEPSP are similar, as are the inputoutput curves across the two conditions (submersion or interface). A change in synaptic inhibition seems not to be involved either, as indicated indirectly by the fact that the width of the fEPSPs is equal across the two conditions.

The signaling pathway through which SB203580, an inhibitor of p38MAPK was able to block our metaplastic effect is not known. However, interestingly, p38MAPK is known to be activated via mGlu receptors (Thomas and Huganir 2004).

\section{Importance of $\mathrm{Mg}^{++}$concentration}

It is remarkable that the concentration of $\mathrm{Mg}^{++}$used is critical in permitting the metaplastic effect described here. It develops when $\mathrm{Mg}^{++}$concentration is $1.0 \mathrm{mM}$ but not when it is $1.3 \mathrm{mM}$.

All the more surprising is that a drastic decrease of $\mathrm{Mg}^{++}$ concentration has the opposite effect. After a transient 30-60 min removal of $\mathrm{Mg}^{++}$, no LTP can be elicited for 2-3 h (Hsu et al. 2000). It seems that this suppression is mediated by the $\mathrm{Ca}^{++}$ influx through the NMDA receptors and through the voltagedependent $\mathrm{Ca}^{++}$channels (VDCC) activated in the seizure-like activity induced by the $\mathrm{Mg}^{++}$-free condition. In our observations, NMDA receptors are certainly not involved, as application of APV during the recovery of the slices does not suppress the effect.

$\mathrm{Mg}^{++}$concentration of $1 \mathrm{mM}$ is important in our paradigm but is not a general condition for observing metaplasticity. While some metaplasticity phenomena were shown in slices bathed in ACSF containing $1.0 \mathrm{mM} \mathrm{Mg}^{++}$(Fitzjohn et al. 1998; Bortolotto et al. 2005), others were observed in presence of $\mathrm{Mg}^{++}$at a concentration of $1.3 \mathrm{mM}$ (Raymond et al. 2000; Woo and Nguyen 2002).

\section{Recruitment of signaling cascades}

It was already known that different induction protocols recruited different signaling cascades (Woo et al. 2003). In mice, for instance, LTP induced by a single high-frequency train is independent of p42/44MAPK (Winder et al. 1999). In contrast, LTP induced by multiple high-frequency trains, theta frequency, or forskolin requires p42/44MAPK (English and Sweatt 1997; Winder et al. 1999; Patterson et al. 2001; Rosenblum et al. 2002). Here, we described a first example of metaplasticity involving the recruitment of signaling cascades. In LTP induced by four electrical trains it is possible that a role is played by the pathway through which the intracellular concentration of $\mathrm{Ca}^{++}$increases. The LTP triggered after recovery in interface is strictly NMDA-dependent; that induced after incubation in submersion is only partly NMDA-dependent. However, other factors must also play a role. Indeed, when FSK and IBMX are applied, the way to increase the 
Interface-interface / Mg++ $1 \mathrm{mM}$
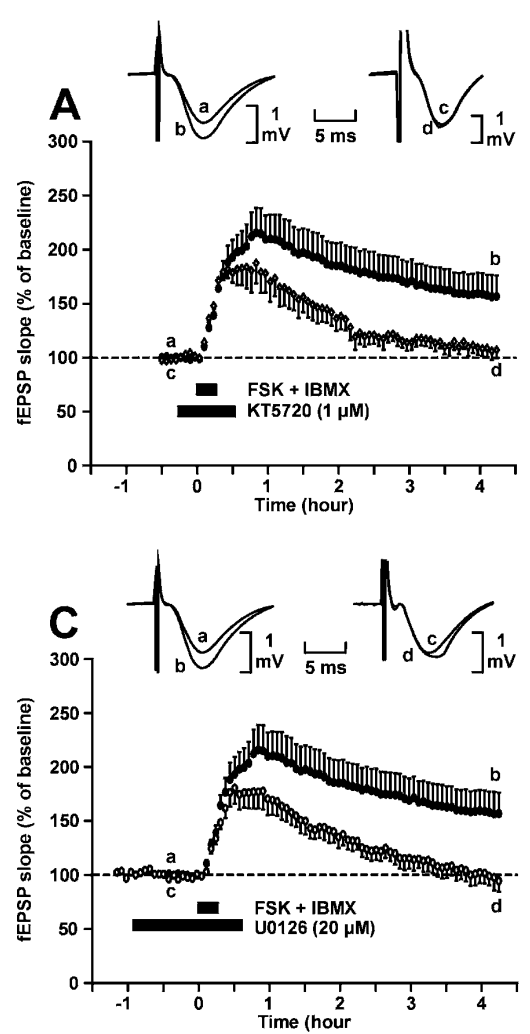

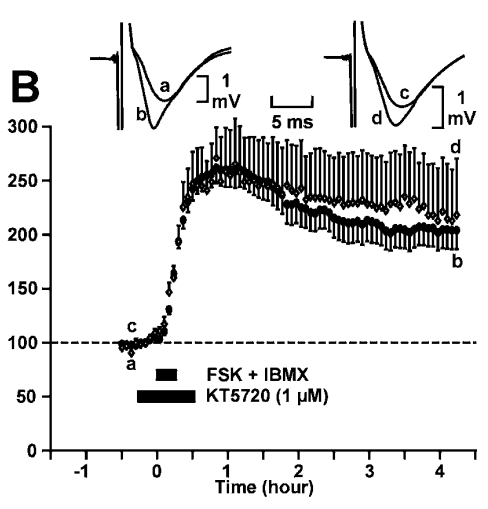

Submersion-interface $/ \mathrm{Mg}^{++} 1 \mathrm{mM}$

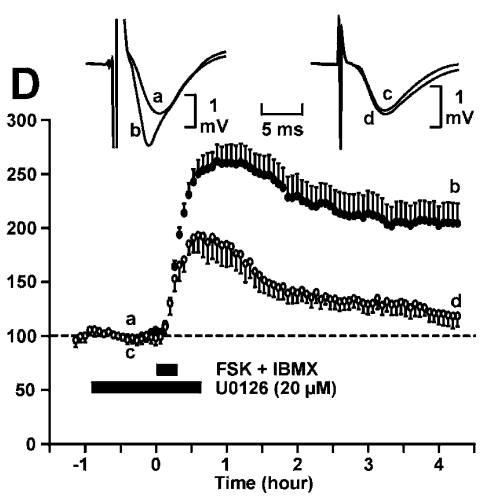

Figure 6. The recruitment of particular kinase cascades in the L-LTP induced by co-application of forskolin (FSK) and IBMX depends on the type of recovery of the slices (in submersion or in interface). $(A, D)$ Each block shows a comparison between the time courses of the potentiation of the fEPSP slope triggered by co-application of FSK and IBMX in the absence (0) or in the presence of either a PKA inhibitor (KT5720) or a MAPK inhibitor (U0126). Slices were allowed to recover in interface in $A$ and $C$, in submersion in $B$ and $D$. Inset: sample of fEPSP traces from one experiment are shown; they were recorded just before $(a, c)$ and $4 \mathrm{~h}$ after $(b, d)$ co-application of FSK and IBMX. Traces $a$ and $c$ were recorded in a control experiment; traces $c$ and $d$ were recorded in an experiment where drug was applied. A,B. Application of a PKA inhibitor (KT5720) impaired the L-LTP induced by FSK-IBMX in the interface-interface condition $A$ but not in the submersion-interface condition $B .(C, D)$ Application of a MEK inhibitor (U0126) impaired the L-LTP induced by FSK-IBMX in both conditions ( $C$ and $D$ ).

intracellular concentration of the secondary messenger (cAMP) involved is the same across the two conditions.

\section{Characteristics of the used submersion procedure}

Here we found that the conditions of incubation (submersion or interface) had a profound influence on the LTP triggered when the slice was maintained in interface. It would have been interesting to see what kind of LTP was generated in the submerged condition after recovery in submersion or interface. However, this experiment could not have been done in symmetrical conditions because of the way the submersion was done in this work. Actually, just after slicing, the slices were placed and maintained in an interface chamber. To obtain submersion conditions, the level of perfusion liquid was raised a few millimeters above the grid and the slices were allowed to float freely near the surface of the liquid. When the interface condition was needed, the level of liquid was lowered accordingly and the slices then rested on the grid. At this stage, it cannot be excluded that our "submerged" slices floating freely near the surface of the slice instead of being maintained with some millimeters of ACSF on top of them could play a role in the described phenomenon.

\section{Implications}

Our results demonstrate that it is possible to dramatically increase the sustaining of LTP by allowing the slices to recover in submersion instead of in interface. Of course, this finding does not question the invaluable aspect of the acute brain slice preparation in LTP and memory research. However, it draws attention to the fact that comparing results obtained in interface and in submersion should be done with caution.

The second finding of this paper concerning the recruitment of the signaling cascades has more conceptual implications. The cell's use of this or that particular signaling cascade to do something at a given moment (LTP in this case) depends on the history of that cell.

\section{Materials and Methods}

\section{Animals}

Male C57BL/6 mice, aged 6-10 wk (Charles River) were used for all the experiments, which were carried out in accordance with National Institutes of Health regulations for the care and use of animals in research and with local ethics committee guidelines.

\section{Electrophysiology}

Transverse hippocampal slices $(400-\mu \mathrm{m}$ thickness) were prepared as described by Nguyen and Kandel (1997). The hippocampus was isolated and sliced with a Mcllwain chopper. Slices were allowed to recover at $28^{\circ} \mathrm{C}$ for $1.5 \mathrm{~h}$ either in submersion or in interface. The rate of flow of the perfused liquid was $2 \mathrm{~mL} / \mathrm{min}$ in submersion and $1 \mathrm{~mL} / \mathrm{min}$ in interface. After this recovery period all the recordings were made in an interface chamber (FST) at $28^{\circ} \mathrm{C}$. Baseline recording started $30 \mathrm{~min}$ later and lasted $30 \mathrm{~min}$. Then LTP was induced either electrically or chemically. Slices were perfused with ACSF with the following composition: $124 \mathrm{mM} \mathrm{NaCl}, 5 \mathrm{mM} \mathrm{KCl}, 26 \mathrm{mM} \mathrm{NaHCO}, 1.0$ $\mathrm{mM} \mathrm{NaH}_{2} \mathrm{PO}_{4}, 2.4 \mathrm{mM} \mathrm{CaCl}_{2}$, either 1.3 or $1 \mathrm{mM} \mathrm{MgSO}_{4}, 10 \mathrm{mM}$ glucose. The ACSF was aerated with $95 \% \mathrm{O}_{2}$ and $5 \% \mathrm{CO}_{2}$. Extracellular fEPSPs were recorded with a glass microelectrode (2-5 Mohm, filled with ACSF) positioned in the stratum radiatum of area CA1. A bipolar nickel-chromium stimulating electrode was used to elicit fEPSPs by stimulation of the Schaffer collateral fibers. Stimulation intensity (0.08 msec pulse duration) was adjusted to elicit fEPSP amplitudes that were around 40\% of maximum size. Basal synaptic transmission was assessed by stimulating Schaffer collaterals once per minute at this test stimulation intensity. Slices that showed maximal fEPSPs $<2 \mathrm{mV}$ were rejected.

LTP was induced electrically by applying either a single 1-sec train $(100 \mathrm{~Hz}$, at test strength) or four 1-sec trains $(100 \mathrm{~Hz}$, test strength) spaced 5 min apart. LTP was also induced chemically by applying $50 \mu \mathrm{M}$ forskolin combined with $30 \mu \mathrm{M}$ IBMX for $15 \mathrm{~min}$.

2-amino-5-phosphonopentanoic acid (APV, Acros organics) was prepared as a concentrated stock solution in $\mathrm{H}_{2} \mathrm{O}$. Cycloheximide (CHX, Sigma), anisomycin (ANI, Sigma), forskolin (FSK, Alomone Labs), and IBMX (Sigma) were all prepared as concentrated stock solutions in dimethyl sulfoxide (DMSO) and then diluted to $0.01 \%$ in ACSF to give their final concentrations. 


\section{Data analysis}

For each slice, the fEPSP slopes were normalized against the average slope over the 30 min before LTP induction. To determine whether or not the normalized fEPSP of a group of slices submitted to the same experimental conditions was significantly potentiated $(P<0.05)$, the baseline percentages measured just before the treatment and $4 \mathrm{~h}$ (unless otherwise specified) after the end of the treatment were compared using a paired Student's $t$-test. The statistical significance $(P<0.05)$ of the difference in increase of the fEPSP measured $4 \mathrm{~h}$ after two different treatments applied to two distinct groups of slices was assessed using a Student's $t$-test.

\section{Acknowledgments}

We are grateful to Peter Nguyen for many pieces of technical advice at the beginning of this work. We thank Christiane Busson for realizing the figures and Ramona Shelby for correcting the English. This investigation was supported by the Queen Elisabeth Fund for Medical Research and by the Belgian National Fund for Scientific Research. Laurence Ris is Research Associate of the Belgian National Fund for Scientific Research.

\section{References}

Abel, T., Nguyen, P.V., Barad, M., Deuel, T., Kandel, E.R., and Bourtchouladze, R. 1997. Genetic demonstration of a role for PKA in the late phase of LTP and in hippocampus-based long-term memory. Cell 88: 615-626.

Abraham, W.C. and Bear, M.F. 1996. Metaplasticity: The plasticity of synaptic plasticity. Trends Neurosci. 19: 126-130.

Abraham, W.C. and Tate, W.P. 1997. Metaplasticity: A new vista across the field of synaptic plasticity. Prog. Neurobiol. 52: 303-323.

Bashir, Z.I., Bortolotto, Z.A., Davies, C.H., Berretta, N., Irving, A.J., Seal, A.J., Henley, J.M., Jane, D.E., Watkins, J.C., and Collingridge, G.L. 1993. Induction of LTP in the hippocampus needs synaptic activation of glutamate metabotropic receptors. Nature 363: $347-350$.

Bliss, T.V.P. and Lomo, T. 1973. Long-lasting potentiation of synaptic transmission in the dentate area of the anaesthetized rabbit following stimulation of the perforant path. J. Physiol. 232: 331-356.

Bliss, T.V.P. and Collingridge, G.L. 1993. A synaptic model of memory: Long-term potentiation in the hippocampus. Nature 361: 31-39.

Bortolotto, Z.A., Bashir, Z.I., Davis, C.H., and Collingridge, G.L. 1994. A molecular switch activated by metabotropic glutamate receptors regulates induction of long-term potentiation. Nature 368: 740-743.

Bortolotto, Z.A., Collett, V.J., Conquet, F., Jia, Z., van der Putten, H., and Collingridge, G.L. 2005. The regulation of hippocampal LTP by the molecular switch, a form of metaplasticity, requires mGlu $_{5}$ receptors. Neuropharmacology 49: 13-25.

Christie, B.R. and Abraham, W.C. 1992. Priming of associative long-term depression by theta frequency synaptic activity. Neuron 8: 79-84.

Cohen, A.S. and Abraham, W.C. 1996. Facilitation of long-term potentiation by prior activation of metabotropic glutamate receptors. J. Neurophysiol. 76: 953-962.

Cohen, A.S., Raymond, C.R., and Abraham, W.C. 1998. Priming of long-term potentiation induced by activation of metabotropic glutamate receptors coupled to phospholipase C. Hippocampus 8: $160-170$.

Collingridge, G.L., Kehl, S.J., and McLennan, H. 1983. Excitatory amino acids in synaptic transmission in the Schaffer collateral-commissural pathway of the rat hippocampus. J. Physiol. 334: 33-46.

Dingledine, R., Dodd, J., and Kelly, J.S. 1980. The in vitro brain slice as a useful neurophysiological preparation for intracellular recording. $J$. Neurosci. Methods 2: 323-362.

English, J.D. and Sweatt, J.D. 1997. A requirement for the mitogen-activated protein kinase cascade in hippocampal long term potentiation. J. Biol. Chem. 272: 19103-19106.

Fitzjohn, S.M., Bortolotto, Z.A., Palmer, M.J., Doherty, A.J., Ornstein, P.L., Schoepp, D.D., Kingston, A.E., Lodge, D., and Collingridge, G.L. 1998. The potent mGlu receptor antagonist LY341495 identifies roles for both cloned and novel mGlu receptors in hippocampal synaptic plasticity. Neuropharmacology 37: 1445-1458.

Frey, U., Huang, Y.-Y., and Kandel, E.R. 1993. Effect of cAMP stimulate a late stage of LTP in hippocampal CA1 neurons. Science 260: $1661-1664$.

Gelinas, J.N. and Nguyen, P.V. 2005. Beta-adrenergic receptor activation facilitates induction of a protein synthesis-dependent late phase of long-term potentiation. J. Neurosci. 25: 3294-3303.

Giese, K.P., Fedorov, N.B., Filipkowski, R.K., and Silva, A.J. 1998. Autophosphorylation at Thr286 of the alpha calcium-calmodulin kinase II in LTP and learning. Science 279: 870-873.

Hille, B. 1992. Ionic channels of excitable membranes (2nd ed.) pp. 607. Sinauer Associates Inc. Publishers, Sunderland, MA.

Ho, O.H., Delgado, J.Y., and O'Dell, T.J. 2004. Phosphorylation of proteins involved in activity-dependent forms of synaptic plasticity is altered in hippocampal slices maintained in vitro. J. Neurochem. 91: $1344-1357$.

Hsu, K.S., Ho, W.C., Huang, C.C., and Tsai, J.J. 2000. Transient removal of extracellular $\mathrm{Mg}^{2+}$ elicits persistent suppression of LTP at hippocampal CA1 synapses via PKC activation. J. Neurophysiol. 84: $1279-1288$

Huang, Y.Y., Colino, A., Selig, D.K., and Malenka, R.C. 1992. The influence of prior activity on the induction of long-term potentiation. Science 255: 730-733.

Kandel, E.R. 2001. The molecular biology of memory storage: A dialogue between genes and synapses. Science 294: 1030-1038.

Lynch, G., Larson, J., Kelso, S., Barrionuevo, G., and Schottler, F. 1983. Intracellular injections of EGTA block induction of hippocampal long-term potentiation. Nature 305: 719-721.

Mannaioni, G., Marino, M.J., Valenti, O., Traynelis, S.F., and Conn, P.J. 2001. Metabotropic glutamate receptors 1 and 5 differentially regulate CA1 pyramidal cell function. J. Neurosci. 21: 5925-5934.

Martin, S., Grimwood, P., and Morris, R.G.M. 2000. Synaptic plasticity and memory: An evaluation of the hypothesis. Annu. Rev. Neurosci. 23: 649-711.

Nguyen, P.V. and Kandel, E.R. 1997. Brief theta-burst stimulation induces a transcription-dependent late phase of LTP requiring cAMP in area CA1 of the mouse hippocampus. Learn. Mem. 4: 230-243.

Nguyen, P.V., Abel, T., and Kandel, E.R. 1994. Requirement of a critical period of transcription for induction of late phase of LTP. Science 265: 1104-1107.

O'Dell, T.J. and Kandel, E.R. 1994. Low-frequency stimulation erases LTP through an NMDA receptor-mediated activation of protein phosphatases. Learn. Mem. 1: 129-139.

Patterson, S.L., Pittenger, C., Morozov, A., Martin, K.C., Scanlin, H., Drake, C., and Kandel, E.R. 2001. Some forms of cAMP-mediated long-lasting potentiation are associated with release of BDNF and nuclear translocation of phospho-MAP kinase. Neuron 32: 123-140.

Raymond, C.R., Thompson, V.L., Tate, W.P., and Abraham, W.C. 2000. Metabotropic glutamate receptors trigger homosynaptic protein synthesis to prolong long-term potentiation. J. Neurosci. 20: 969-976.

Rosenblum, K., Futter, M., Voss, K., Erent, M., Skehel, P.A., French, P., Obosi, L., Jones, M.W., and Bliss, T.V. 2002. The role of extracellular regulated kinases I/II in late-phase long-term potentiation. J. Neurosci. 22: 5432-5441.

Shigemoto, R., Kinoshita, A., Wada, E., Nomura, S., Ohishi, H., Takada M., Flor, P.J., Neki, A., Abe, T., Nakanishi, S., et al. 1997. Differential presynaptic localization of metabotropic glutamate receptor subtypes in the rat hippocampus. J. Neurosci. 17: 7503-7522.

Thomas, G.M. and Huganir, R.L. 2004. MAPK cascade signaling and synaptic plasticity. Nat. Rev. Neurosci. 5: 173-183.

Winder, D.G., Martin, K.C., Muzzio, I.A., Rohrer, D., Chruscinski, A., Kobilka, B., and Kandel, E.R. 1999. ERK plays a regulatory role in induction of LTP by theta frequency stimulation and its modulation by beta-adrenergic receptors. Neuron 24: 715-726.

Woo, N.H. and Nguyen, P.V. 2002. "Silent" metaplasticity of the late phase of long-term potentiation requires protein phosphatases. Learn. Mem. 9: 202-213.

Woo, N.H., Duffy, S.N., Abel, T., and Nguyen, P.V. 2003. Temporal spacing of synaptic stimulation critically modulates the dependence of LTP on cyclic AMP-dependent protein kinase. Hippocampus 13: 293-300.

Zhang, L., Kirschstein, T., Sommersberg, B., Merkens, M., Manahan-Vaughan, D., Elgersma, Y., and Beck, H. 2005. Hippocampal synaptic metaplasticity requires inhibitory autophosphorylation of $\mathrm{Ca}^{2+} /$ calmodulin-dependent kinase II. J. Neurosci. 25: 7697-7707.

Received November 9, 2005; accepted in revised form February 9, 2006. 


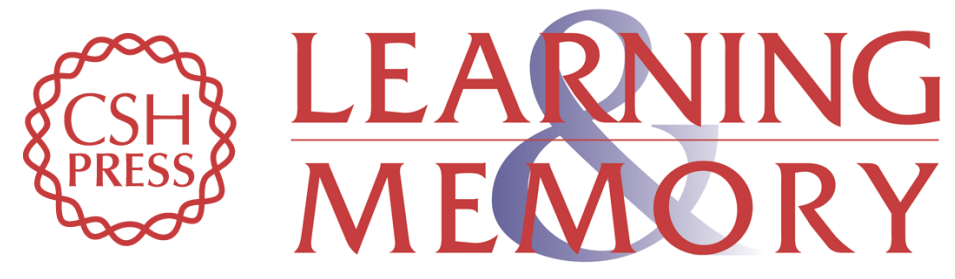

\section{The characteristics of LTP induced in hippocampal slices are dependent on slice-recovery conditions}

Brigitte Capron, Christian Sindic, Emile Godaux, et al.

Learn. Mem. 2006, 13:

Access the most recent version at doi:10.1101//m.135406

References This article cites 37 articles, 15 of which can be accessed free at:

http://learnmem.cshlp.org/content/13/3/271.full.html\#ref-list-1

License

Email Alerting Receive free email alerts when new articles cite this article - sign up in the box at the Service top right corner of the article or click here. 